\title{
Logic and Computer Educational Game for non-IT Vocational Students
}

\author{
Annisa Larasati ${ }^{1}$, Harsa Wara Prabawa ${ }^{2}$, Jajang Kusnendar ${ }^{3}$ \\ \{annislarast@gmail.com ${ }^{1}$, harsawara@upi.edu ${ }^{2}$, jkusnendar@upi.edu ${ }^{3}$ \}
}

Universitas Pendidikan Indonesia ${ }^{1,2,3}$

\begin{abstract}
This research aims to build an educational game that can be used as a learning aid, especially in the content of logic and computer algorithms and measuring the effectiveness of the use of educational games on increasing student understanding. This research is development research, in which media prototype design is tested several times to different subjects to get a media design that suits your needs. Contextual relation to understanding, the media tested on 103 students in one of the non-IT Vocational High Schools. From the results, students gave excellent responses regarding this educational game. The majority of students think that this game is exciting, and can help provide understanding and increase student motivation. However, this educational game is only able to help students understand at the low order level of thinking. for more complex problem-solving cases, other media assistance needed in constructing student understanding to a higher level.
\end{abstract}

Keywords: Game-based learning, Logic, Computer Algorithms

\section{Introduction}

Technological progress is a necessity that cannot be avoided in this life because technological progress goes hand in hand with advances in science. Every innovation is created to provide positive benefits for human life. It offers many conveniences, as well as a new way of doing human activities. Likewise, education. The global demand demands the world of knowledge to always and continuously adjust technological developments to efforts in improving the quality of education, especially changing the use of information and communication technology for the world of education, especially in the learning process. Information technology in school can be understood as a complex, integrated process involving people, ideas, tools, and organizations to analyze problems, find ways to overcome difficulties, implement, assess, and manage problem-solving that covers all aspects of human learning.

One form of information technology that is often used in learning is learning media. Media, in general, can be defined as a means to convey information. Concerning learning, various forms of media have been used to present information and support the learning process. Therefore, it is essential to adjust the choice of media with the material to give. The selection of appropriate learning media in addition to facilitating the process of transfer of knowledge between teacher and students, can also arouse the desire and interest in learning, 
arouse motivation and stimulation of learning, even bring psychological influences on students [1] [2]

The importance of the role of mapped media in learning in one of the Vocational High Schools in the City of Bandung, where the fact is found that the interests of Vocational High School students in learning theoretical material that is not a field of expertise are very low. It is partly because students consider the content not directly related to the skills needed in their vocational areas, contextual content that seems 'absurd'. After all, sometimes it is taught without the help of media and adequate practical activities.

As a result, the chances of students experiencing misconceptions increase. For example, when discussing how to write a flowchart, sometimes students fail to distinguish between input and process because they both use verbs. Also, students often experience decreased motivation to learn, due to the absence of practice using a computer, because the contents of the material discussed are limited to basic concepts without further discussion such as programming.

On the other hand, the majority of students 'difficulties in learning programming, usually stem from students' desire to complete the task at the same time [3]. It has the potential to lead to overgeneralization and misapplication of analogy [4]. Overgeneralization can be understood as a tendency in students to see a case/condition in programming as an event that does not change so that we tend to make generalizations. Meanwhile, the misapplication of analogy is interpreted as a mental process where students tend to create representations of certain concepts by taking similarities (to make it easier for them to remember and understand concepts), but the similarities used are not quite right to represent the concept.

Literature studies conducted by Huang, Huang, and Tschoopp reveal that elements are essential for starting and maintaining learning, and learning performance is motivation [5]. Therefore, learning activities need to be designed so that they can provide an adequate level of motivational stimulation. Consequently, it is not surprising to say that all the potential possessed by the game as a medium is possible to be used as a learning medium [6]. Its ability to influence the cognitive and emotional aspects of the user simultaneously can be a strength for learning media.

This research aims to build game-based learning that can be used as a learning aid, especially in the material of logic and computer algorithms, as well as to measure the effect of game use on increasing student understanding. Utilization of games in real learning aims to provoke student interest [7] [8] in learning material while playing, so that with feelings of pleasure felt, it is hoped students can more easily understand the learning material presented [9] [10].

\section{Methods}

This research is development research, in which media prototype design is tested several times to different subjects to get a media design that suits your needs. To understanding, the media were tested on 103 students in one of the non-IT Vocational High Schools in the Bandung City area.

In general, research data retrieval is carried out in 2 main scenarios, namely outside the learning hours and during the learning process. Situations outside the hours of learning are done to provide opportunities for students to gain experience in playing games that have been made. This scenario targets outcomes in the form of short-term memory for students, 
especially those related to students' knowledge in completing each of the challenges provided. The duration submitted to explore the playing experience is seven days, or one week before the next learning meeting is held. Students' involvement in playing the game will be used as capital to construct their knowledge of the material to be learned because the game gameplay is designed to be associated with the content that students must learn.

This scenario is more similar to the flipped classroom scenario, which makes learning activities at home as a means to explore as much information and experience while learning activities at school are intended to enrich knowledge and experience.

\section{Results}

Material logic concepts and computer algorithms have two items Basic Competence (KD), namely [11]: 3.1) Applying computer logic and algorithms; 4.1) Using command functions. Competency Achievement Indicators (GPA) are divided into two aspects, namely: 1. Knowledge in which there are two points, 1) Explain the concepts of Logic and Algorithms, 2) compile a flowchart of simple algorithm examples in daily life, and 2. aspects of skills, namely skilled in using commands based on functions in organizing the algorithm. The scope of the material taught is as follows: definition of logic and algorithm, characteristics of the algorithm, underlying structure of the algorithm, how to write an algorithm, and flowchart notation

The content that will be presented in the media is related to the material taught in learning logic and computer algorithms, but will be arranged in such a way as to be a plot or storyline in the game, and not presented as contained in the book (see Figure 1).

\subsection{Game-based learning Element}

Features are things that can distinguish every game there. The highlight of this Gamebased learning is that the material contained in this game is integrated with the storyline or the plot of the game, the core of the game itself is actually material that has been disguised, including the rules, missions or challenges in the game, even the background of the game, which delivered through conversations between characters.

While the gameplay is a guaranteed way in which users interact with the game. Based on a poll of the ten best game genres, which is still taking place on the international website "The Top Tens" [12], RPG gets the most popular first place; besides that, the RPG game also deserves to be used as a learning aid. For the gameplay itself this game is quite easy to control, i.e., use the "space" or "enter" key to make choices, the "escape" or "X" key to cancel each command, and use the directional keys to move the cursor or to run the character played. Also, the pattern in completing each stage will be the same, which is gathering information in villages or cities, exploring the labyrinth, fighting boss monsters, then answering fairy questions to be able to carry the magic stone. The difference is only the appearance and level of difficulty.

Figure 2 shows the appearance when the monsters attack, basically, these little monsters do not have a connection with the material, it's just that it has a pretty significant attachment in terms of its gaming system, which is in addition to being a challenge so that the game is more exciting, even these small monsters will give prize money and items when they are defeated, 
and on the other hand can increase exp to level up so that the user's character becomes stronger.

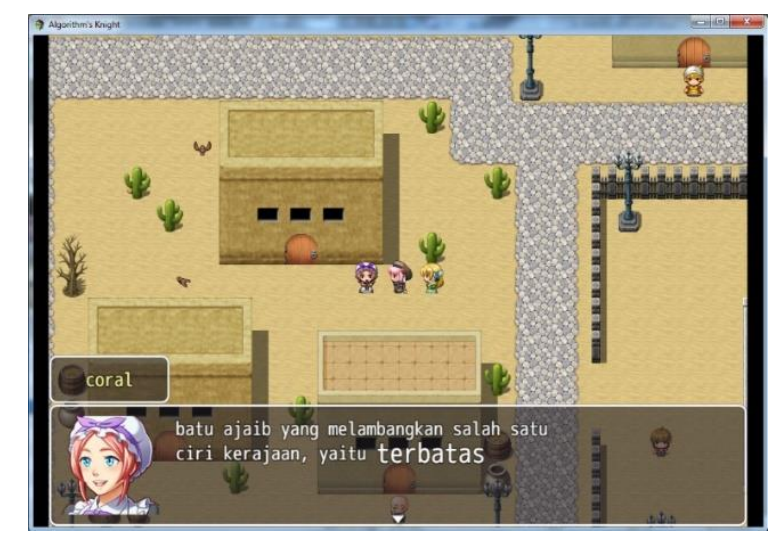

Fig. 1. An example of a game feature, a dialog containing material disguised as a game flow.

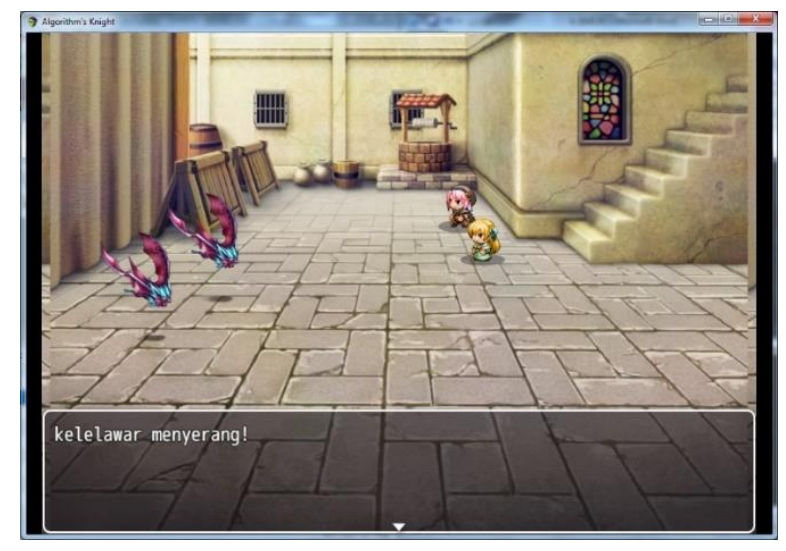

Fig. 2. Attack monsters as a seasoning game.

Level design is planning in making a game that includes the style, background, and storyline of a game. The plot or storyline of this Game-based learning tells the adventure of a young man who saved a kingdom from an evil king by collecting magic stones from four villages around the kingdom, while the setting is located in the kingdom's territory, namely 4 villages with each labyrinth, city, and in the palace, and regarding the style or presentation style of each stage, from stage one to four (in the village) will be the same, i.e., the player will collect information from villagers on how to get to the labyrinth, and information about the magic stone, after the information data collected, the player will enter the maze and face guard monsters as well as boss bosses, if the boss has lost a stone guard fairy will appear to give questions for the final test, if the problem is answered then the player will get a magic stone and an additional gift from the guard fairy in the form of fighting equipment and secret scrolls 
of magic stone strength, but if the wrong player answer then he will be thrown out of the maze and fight the guardian monsters again. Figure 3 follows the flow illustration for stages 1-4.

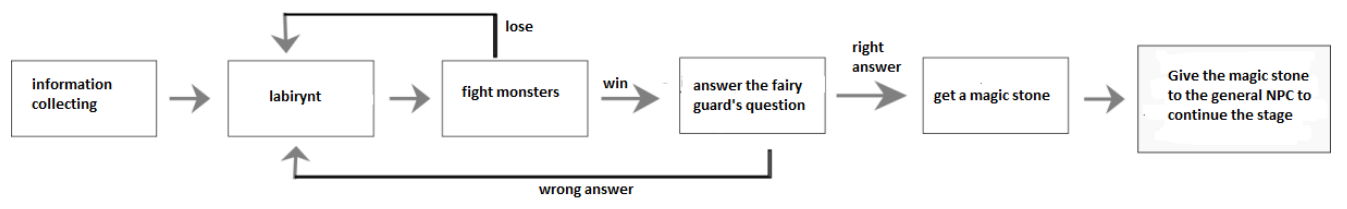

Fig. 3. General game flow.

As for what distinguishes each step is the level of difficulty in fighting monsters because each step has a specific minimum level limit (using a level scenario). Which even though the player has obtained the requirements (have collected magic stones) if the level is not enough, then the player will not be able to enter the next stage.

The presentation style on stage 5 (in the city and kingdom) will be slightly different from the previous step. That is, to complete this stage the player must first ask all residents to find a boss monster disguised as a citizen in the city to open the way to the labyrinth that connects the town with the kingdom, in the maze, there will be no boss monsters, but small monsters can at any time -time attack. In this maze, players will learn about repetition and branching. In the royal palace there will be no unique material, players only have to fight the guard army, and defeat the evil king Aar Kral, so that if finally won, then the player will be crowned as the new king, but must first answer the evaluation, which is five questions first.

\section{Discussion}

Based on the results of data processing that has been done after the application of the class of research objects, it can be seen that Game-based learning that has been designed by researchers gets an assessment in the category of Very Good. This can be due to the development of Game-based learning to help the process of learning logic, and computer algorithms have been done well, but somethings still need to be considered so that the validation of media experts has not shown perfect results. Researchers base that there are still shortcomings in Game-based learning that hopes can be increased later. Among them is the absence of an explanatory audio effect on the video illustration (dubbing) on the video shown, At least examples of illustrated material contained in the video, it would be better if the cases of drawings are improved so that students have the opportunity to better understand the application of computer logic and algorithms to life daily, and the duration of dialogue between characters when they start the game (intro) is too long, so that makes some students who are lazy to read feel bored. But researchers see that in terms of content, interface appearance, gameplay, and mission displayed in the game is quite good

The influence of Game-based learning on increasing student understanding for each class can be categorized quite well, based on the results of the questionnaire distributed to students, $72 \%$ of students think that Game-based learning is beneficial in improving understanding, $23 \%$ believe this game helps, and $4 \%$ thought it did not help improve comprehension. In the gain review, it can be seen that the gain value obtained by the upper class gets the highest amount of 0.71 (High), which is proportional to the amount of the responses given by upperclass students regarding all aspects of this Game-based learning, with an average percentage average every element is $98 \%$. This proves that Game-based learning is instrumental in 
improving the ability of students in upper-class groups. Not much different from the upper class, students in the middle group gain 0.70 (High) with an average percentage of each aspect of Game-based learning of $95.28 \%$. Students in the lower class show the most significant difference, besides getting again that is "Medium" (0.51), although the responses given in Game-based learning are still classified as very high, but not as high as the upper class and middle class, the average percentage each aspect is 89.19 . When viewed from the average rate given by students for each element, it can be seen if students offer a less value in the aspects of Information Structure, documentation, as well as the quality of the content, which of the three are presented in the form of dialogue in the game or it, can be concluded that lower grade students are a little difficulty in digesting readings

In general, students give responses regarding the application of this Game-based learning for learning logic and computer algorithms that are interesting. The content is easy to understand; fun teaches inaccuracy and invites to cultivate reading.

Of the 103 students who tried Game-based learning, 68\% of them thought that Gamebased learning was exciting, $27 \%$ thought this game was impressive, and $5 \%$ found it unattractive. The content that according to students is the most influential in making exciting Game-based learning is the display of $35 \%$, mission $25 \%$, gameplay content gets $20 \%$, Gamebased learning plot or 17\%, and 3\% answered others, which is of the opinion that the Gamebased learning is a little strange, but after a long time playing more and more, the plot is increasingly impressive.

In terms of the influence of the application of Game-based learning on increasing understanding, $72 \%$ of students think that Game-based learning is beneficial in increasing knowledge, $23 \%$ believe this game helps, and $4 \%$ think it doesn't help increase understanding. With content that plays an important role is the Game-based learning plot or story getting $32 \%$ points, $30 \%$ gameplay, $24 \%$ mission, and $14 \%$ appearance.

While the students' responses regarding the effect of Game-based learning on increased learning motivation, $73 \%$ of students thought that Game-based learning was beneficial in improving their learning motivation, and the remaining 27\% thought this Game-based learning. "Helped" to improve motivation student learning.

Also, $73 \%$ of them or as many as $16 \%$ said that their grades could be significantly improved, while $27 \%$ of them or as many as six students said that their grades had improved somewhat. The things that according to students, affect increasing the value of these students are the presentation of material in Game-based learning that is easy to understand, video illustrations that are displayed at each end of the stage, plot, mission, and appearance of Game-based learning.

\section{Conclusion}

In general, this research reveals the problem of programming learning, one of which is caused by the difficulty of drafting concepts that must be used in solving all issues. A good understanding of the structure of the idea, of course, will also increase both the ability of students to solve difficulties. The game developed provides a stimulus that consists of scenarios/games that can be played with learning or in other words, creating a memory framework to facilitate students in understanding the concepts they need to understand. The game that was developed was designed to be able to create as many memory cycles as possible, representing students who could quickly get contextual programming concepts. From 
the results of this study note that in general, students gave an excellent response regarding this educational game. The majority of students think that this game is exciting, and can help provide understanding and increase student motivation. However, this educational game can only help students understand at a low level of thinking. For more complex problem-solving cases, other media assistance is needed in building student understanding to a higher level. This critical pattern also opens up opportunities for developing game ideas for other learning content.

\section{References}

[1] Kleiman, G. M.: Myths and Realities About Technology in K-12 Schools. The Online Journal of the Leadership and the New Technologies Community. pp. 1-8 (2001)

[2] DeBruyckere, P., Kirschner, P. A., and Hulshof, C. D.: Urban Myths about Learning and Education. 1st edition ed.. New York: Academic Press (2015)

[3] Du Boulay, B.: Some Difficulties of Learning to Program. Journal of Educational Computing Research (1986)

[4] Bower, M. and Falkner, K.: Computational Thinking, The Notional Machine, Pre-service Teacher and Research Opportunities. in Proceeding of The 17th Australasian Computing Education Conference (ACE 2015). Australia (2015)

[5] Huang, W.-H., Huang, W. Y., and Tschopp, J.: Sustaining iterative game playing processes in DGBL: The relationship between motivational processing and outcome processing. Computers and Education. pp. 789-797 (2010)

[6] Kapp, K. M.: The Gamification of Learning and Instruction: Game-Based Methods and Strategies for Training and Education. San Francisco: Pfeiffer \& Company (2012)

[7] Ho, P.-C., Chung, S.-M., and Tsai, M.-H.: A Case Study of Game Design for E-Learning. In Technologies for E-Learning and Digital Entertainment. Hangzhou (2006)

[8] Gunter, G. A., Kenny, R. F., and Vick, E. H.: Taking Educational Games Seriously: Using the RETAIN Model to Design Endogenous Fantasy into Standalone Educational Games. Educational Technology Research and Development. pp. 511-537 (2008)

[9] Firdausi, N., Prabawa, H. W., and Sutarno, H.: Improve Student Understanding Ability Through Gamification in Instructional Media Based Explicit Instruction. Journal of Physics: Conf. Series (2017)

[10] Rose, J., O'Meara, J., Gerhardt, T. , and Williams, M.: Gamification: using elements of video games to improve engagement in an undergraduate physics class. Physics Education, 51(5), (2016)

[11] Direktorat Pembinaan Sekolah Menengah Kejuruan - Kementrian Pendidikan dan Kebudayaan, Keputusan Direktur Jenderal Pendidikan Dasar dan Menengah No.30/D.D5/KEP/KR/2017 tentang Kompetensi Inti dan Kompetensi Dasar SMK/MAK, Jakarta: KEMDIKBUD (2017)

[12] G. Garth, 10 September 2019. [Online]. Available: https://www.thetoptens.com/video-gamegenres/ (2019) 